\title{
Total Energy Expenditure and Physical Activity in Children Treated with Home Parenteral Nutrition
}

\author{
LAURENT BÉGHIN, LAURENT MICHAUD, RÉGIS HANKARD, DOMINIQUE GUIMBER, \\ EVELYNE MARINIER, JEAN-PIERRE HUGOT, JEAN-PIERRE CÉZARD, \\ DOMINIQUE TURCK, AND FRÉDÉRIC GOTTRAND
}

\begin{abstract}
Division of Gastroenterology, Hepatology and Nutrition, Department of Paediatrics, Jeanne de Flandre University Children's Hospital and Faculty of Medicine, Lille, France [L.B., L.M., D.G., D.T., F.G.]; Clinical Research Center, CIC-9301-INSERM-CHU, University Hospital, Lille, France [L.B.]; Clinical Research Center CIC-9202-INSERM-AP-HP [R.H.], Division of Gastroenterology, Hepatology and Nutrition [E.M., J.-P.H., J.-P.C.], Robert Debré University Children's Hospital, Paris, France
\end{abstract}

\begin{abstract}
Determining total energy expenditure (TEE) and its components in children treated with home parenteral nutrition (CHPN) under free-living conditions is an important consideration in the assessment of energy requirements and the maintenance of health. The aim of this study was to assess TEE and physical activity in CHPN. Eleven CHPN (three girls and eight boys; median age, $6.0 \mathrm{y}$; range, 4.5-15.0 y) were compared with 11 healthy children (three girls and eight boys; median age, $6.0 \mathrm{y}$, range, 4.5-14.0 y) after pairing for sex, age, and weight. Underlying diseases included chronic intractable diarrhea $(n=5)$, short bowel syndrome $(n=3)$, and intestinal dysmotility $(n=3)$. None of these children had inflammatory disease or recent infection when studied. Fat-free mass (FFM), measured by body impedance analysis, fat mass (FM), measured by skinfold thickness, and energy intake were similar between the two groups, suggesting that CHPN had normal body composition and energy intake. Resting energy expenditure (REE), measured by indirect calorimetry, and TEE, assessed by a technique using 24-h heartrate monitoring calibrated against indirect calorimetry and physical activity using a triaxial accelerometer, were simultaneously recorded and were also similar in the two groups. Sleeping energy expenditure (SEE), expressed per kilogram of FFM, was significantly greater in the CHPN group (median, 0.15 ; range, $0.10-0.23 \mathrm{~kJ} / \mathrm{min} / \mathrm{kg}$ FFM versus median, 0.12; range, 0.09-
\end{abstract}

\section{ABSTRACT}

$0.21 \mathrm{~kJ} / \mathrm{min} / \mathrm{kg}$ FFM for controls; $p<0.05$, Wilcoxon rank test). These findings were explained by the high correlation between the energy flow infused by parenteral nutrition and sleeping energy expenditure ( $p<0.05$, Spearman test) and also-diet induced thermogenesis $(p<0.05$ Spearman test). These results suggest that the energy requirements of children on long-term home parenteral nutrition programs do not differ from controls and that cyclic parenteral nutrition does not interfere with physical activity. (Pediatr Res 53: 684-690, 2003)
BMI, body mass index
Abbreviations
EE, energy expenditure
DIT, diet-induced thermogenesis
FFM, fat-free mass
FM, fat mass
HPN, home parenteral nutrition
HR, heart rate
HRMT, heart rate monitoring technique
IC, indirect calorimetry
REE, resting energy expenditure
SEE, sleeping energy expenditure
TEE, total energy expenditure

Parenteral nutrition (PN) is a lifesaving procedure in children with gastrointestinal tract failure, which is defined as inadequate absorption of nutrients and electrolytes and in-

Received February 8, 2002; accepted September 12, 2002.

Correspondence: Professor F. Gottrand, Unité de Gastroentérologie, Hépatologie et Nutrition, Clinique de Pédiatrie, Hôpital Jeanne de Flandre, 2, Avenue Oscar Lambret, F59037 Lille Cedex, France; e-mail: fgottrand@chru-lille.fr

Supported by a grant from the French Ministry of Health (Hospital Program for Clinical Research; 1997, Grant Number 1901).

DOI: 10.1203/01.PDR.0000057208.05549.3B cludes diseases such as chronic intractable diarrhea, short bowel syndrome, and severe intestinal dysmotility (1). This technique is used to supply the appropriate nutrients and fluids to these children, and has recently been used increasingly both in hospitals and at home (2), resulting in an appreciable improvement in these patients' well-being (3). Estimation of the energy requirements of children treated with HPN (CHPN) is an important consideration in the maintenance of their health. Energy requirements vary according to age, medical condition, and nutritional status. Several methods can be used 
to estimate nutrient intake. These are based on anthropometric, biochemical, clinical, and dietary parameters (4-7). TEE takes into account basal metabolic rate, physical activity (PA), growth, DIT, fecal losses, and maintenance of body temperature. However, CHPN are often troubled by the inconvenience of restricted oral food intake, high intestinal output, and the presence of a stoma or catheter. Moreover, PN is a timeconsuming and intrusive procedure. These factors may impose severe restrictions on diurnal life in terms of social and leisure activities and PA. The high proportion of energy intake supplied to these patients intravenously instead of via the digestive tract may influence food metabolism, and, thus, a change in EE should be anticipated. These drawbacks may affect the EE and PA of these children, and consequently their energy requirements. The aim of this study was to assess TEE and PA in CHPN.

\section{PATIENTS AND METHODS}

Subjects. Twenty-two nonobese children participated in this study. Eleven were receiving cyclic HPN for underlying diseases, including chronic intractable diarrhea $(n=5)$, short bowel syndrome $(n=3)$, and intestinal dysmotility $(n=3)$. CHPN were clinically stable, with no evidence of active inflammatory disease, and had not had surgery for at least 2 mo before evaluation. Six CHPN wore a stoma. Eight were prepubertal, and three subjects were postpubescent. At the time of the study, children had been receiving PN for a median of 36 wk (range, 10-84 wk). Minerals, trace elements, and vitamins were provided according to the recommended intake (8). All patients received $12-16 \mathrm{~h}$ of nocturnal $\mathrm{PN}$ on a median cycle of $5 \mathrm{~d}$ (range, 2-7). PN provided $66.4 \%$ (range, $15.4-100 \%$ ) of the total energy intake of CHPN (Table 1). Total energy intake was in accordance with the French recommended dietary allowances and was similar between the two groups (9). There was no difference in the distribution of glucids, proteins, and fat in the total energy intake between the two groups. The median (range) infusion rate per kilogram of weight was 17.8 $\mathrm{mg} / \mathrm{min} / \mathrm{kg}(8.8-27.2 \mathrm{mg} / \mathrm{min} / \mathrm{kg})$ for glucose, $2.5 \mathrm{mg} / \mathrm{min} / \mathrm{kg}$ $(1.5-3.5 \mathrm{mg} / \mathrm{min} / \mathrm{kg}$ ) for amino acids, and $2.2 \mathrm{mg} / \mathrm{min} / \mathrm{kg}$ $(1.2-2.9 \mathrm{mg} / \mathrm{min} / \mathrm{kg}$ ) for fats. Energy intake by PN was distributed as $67.6 \%$ glucose $(60.9-75.5 \%), 10.5 \%$ amino acids (6.6-13.2\%), and $20.9 \%$ fats $(11.3-28.8 \%)$. When food consumption was taken into account, the relative distributions of glucids, proteins, and fats in total energy intake were $44.2 \%$

Table 1. Repartition of total energy intake in the two groups of children

\begin{tabular}{lcc}
\hline & \multicolumn{1}{c}{ Parenteral } & Controls \\
\hline Oral intake $(\mathrm{kJ} / \mathrm{kg} / \mathrm{d})$ & $128.1(0-341.8)$ & $216.9(62.1-296.8)$ \\
Parenteral intake $(\mathrm{kJ} / \mathrm{kg} / \mathrm{d})$ & $216.9(62.1-296.8)$ & 0 \\
Total energy intake $(\mathrm{kJ} / \mathrm{kg} / \mathrm{d})$ & $294.3(216.9-404.0)$ & $300.9(217.0-480.0)$ \\
Ratio P/O intake (\%) & $66.4(15.4-100)$ & 0 \\
Ratio EI/RDA (\%) & $96.6(72.1-132.4)$ & $94.3(84.3-145.7)$ \\
Protein intake (\%) & $15.5(11.6-18.0)$ & $12.9(11.3-20.8)$ \\
Fat intake (\%) & $38.7(14.6-57.8)$ & $35.7(28.6-42.0)$ \\
Glucid intake (\%) & $44.2(26.5-70.9)$ & $51.5(37.4-60.3)$ \\
\hline
\end{tabular}

Data given as median and range. EI, energy intake; RDA, recommended dietary allowances.
(26.5-70.9\%), 15.5\% (11.6-18.0\%), and 38.7\% (14.6-57.8\%), respectively. Five children were nourished by PN only, and the remaining six were fed orally to a limited extent. CHPN were recruited from the Jeanne de Flandre Hospital, Lille, France ( $n$ $=7)$, and the Robert Debré Hospital, Paris, France $(n=4)$. Children with malignancies, cystic fibrosis, or Crohn disease were excluded. Control children were recruited from among the children of the staff at the Jeanne de Flandre University Children's Hospital $(n=11)$. All control children passed a thorough physical and medical examination and were considered healthy. None of these children had inflammatory disease or recent infections when studied and had no medical history that could modify EE metabolism. CHPN had frequent biologic check-ups, including serum inflammatory markers, anemia, and other serum biochemical parameters in the routine follow-up. All measurements for serum inflammatory markers, anemia, and other serum biochemical parameters were normal in each patient. None of them presented renal impairment or blood electrolytic disturbance at the time of the study. Body temperature was normal for all subjects before the IC calibration procedure and the TEE measurement.

All control subjects were paired for age, weight, and pubertal status with CHPN (Table 2).

Before the study began, the purpose and objectives were carefully explained to each subject. Informed consent was obtained from the children and their parents. The study was approved by the Lille University Research Ethics Committee (Comité Consultatif de Protection des Personnes dans la Recherche Biomédicale, Lille, France). All procedures were performed in accordance with the ethical standards of the Helsinki Declaration of 1975, as revised in 1983, and French Good Clinical Practices (1987).

Body composition. On the day of the test, each child arrived by car at the Clinical Investigation Center of Lille (CIC-9301INSERM-CHU) or Paris (CIC-9202-INSERM-AP-HP) at $0800 \mathrm{~h}$. Control subjects fasted from $2000 \mathrm{~h}$ the previous day, and parenteral infusion was interrupted by $0800 \mathrm{~h}$ on the previous day for CHPN (Fig. 1). Weight and height were measured. The child then rested recumbent on a hospital bed for $15 \mathrm{~min}$. Body resistance was measured using a body impedance 50-Hz meter (BIA 101/S, RJL Systems, Clinton Township, MI, U.S.A.), and FFM was calculated with the Schaefer formula (10).

Left skinfold thicknesses (triceps, biceps, subscapular, and suprailiac) were measured to the nearest $0.1 \mathrm{~mm}$ with a Har-

Table 2. Anthropometric characteristics and body composition in two groups of 11 children

\begin{tabular}{lcc}
\hline & Parenteral & Controls \\
\hline Age $(\mathrm{y})$ & $6.0(4.5-15.0)$ & $6.0(4.5-14.0)$ \\
Weight $(\mathrm{kg})$ & $22.5(17.4-55.0)$ & $20.9(17.0-49.2)$ \\
Height $(\mathrm{cm})$ & $114.0(103.0-158.0)$ & $119.0(105.0-163.0)$ \\
Z-score $(\mathrm{W} / \mathrm{A})$ & $0.6(-2.5-3.3)$ & $0.5(-0.7-2.5)$ \\
Z-score $(\mathrm{H} / \mathrm{A})$ & $-0.3(-5.14-2.1)$ & $0.5(-1.2-3.8)^{*}$ \\
BMI $\left(\mathrm{kg} / \mathrm{m}^{2}\right)$ & $16.9(15.5-22.0)$ & $15.2(14.2-18.6)^{* *}$ \\
FFM $(\mathrm{kg})$ & $17.6(13.2-38.4)$ & $17.5(13.5-39.5)$ \\
FM $(\%)$ & $20.7(10.3-4.8)$ & $14.9(11.4-19.1)$ \\
\hline
\end{tabular}

Data given as median and range. A, age.

** $p<0.01 ; * p<0.05$ Wilcoxon rank test. 


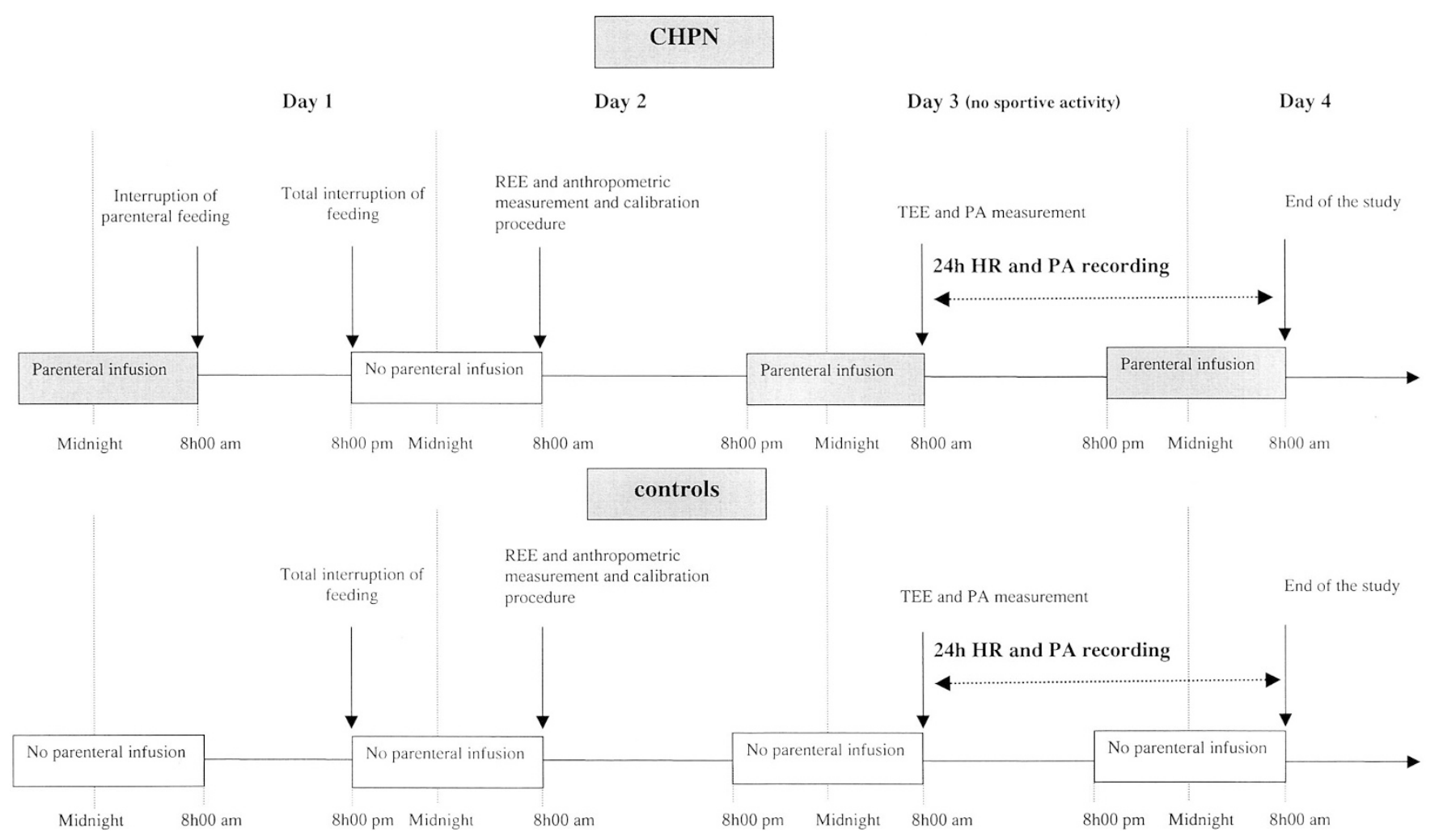

Figure 1. Study protocol describing all events according to time for HPN patients and controls.

penden caliper (Holtain Ltd, Crymmych, U.K.). FM was calculated using either the Brook formula for children under $12 \mathrm{y}$ old (11) or the Durnin formula for children over 12 y (12). $\mathrm{Z}$-score height/age and weight/age were calculated using Sempé's tables (13). As patients treated with HPN were studied at two centers - in Lille and Paris - two different observers were involved in gathering the anthropometric data. The Harpenden calipers were similar in the two centers and the two observers (L.B. in Lille and R.H. in Paris) trained together and were tested with this technique. The equipment and procedures to assess anthropometric data were strictly the same.

Energy intake. Energy intake was evaluated for $7 \mathrm{~d}$ before the study. Subjects recorded diurnal food intake or PN infusion on a specific report form. Instructions were given to each patient or the patient's parents on how to keep accurate records, and the parents assisted the children in identifying, quantifying, and recording the foods consumed. Dietary records were checked by a dietitian and analyzed using BILNUT software (Nutrisoft version 6, Paris, France) $(14,15)$. For CHPN, total energy intake was the sum of the oral food intake and $\mathrm{PN}$.

TEE. TEE was assessed by the 24-h HRMT calibrated against IC. For standardization, all subjects were studied on a school day that had no sporting activities. Twenty-four-hour TEE was studied in CHPN on a day when they had received nocturnal PN. HRMT was performed as previously reported $(16,17)$. This technique is accurate, noninvasive, inexpensive, robust, socially acceptable, and indicates the pattern of the activity, i.e., diurnal energy expenditure (DEE) and SEE can be computed separately from TEE. In brief, this technique in- volves a two-step procedure. First, there is a calibration period that includes different activities such as resting and postprandial periods and different levels of PA on a cycle ergometer, during which the HR is simultaneously recorded together with EE measured by IC using a Deltatrac II (Datex Omheda, Helsinki, Finland). This calibration period is used to define an individual polynomial third-order equation (P3) between the $\mathrm{HR}$ and EE data. Then, HR is recorded minute-by-minute for $24 \mathrm{~h}$ using a Holter recorder. Finally, EE is computed using P3 and HR data of the 24-h recording. SEE was computed using a method recently developed (18). Briefly, a threshold point called an inflection point (IP) is defined on each individual P3 equation. The individual $\mathrm{P} 3$ describing the relationship of $\mathrm{HR}$ to $\mathrm{EE}\left(\mathrm{EE}=\mathrm{a} \times \mathrm{HR}^{3}+\mathrm{b} \times \mathrm{HR}^{2}+\mathrm{c} \times \mathrm{HR}+\mathrm{d}\right.$; where $\mathrm{a}$, $\mathrm{b}, \mathrm{c}$, and d are numeric factors) was derived as $\mathrm{EE}^{\prime}=\alpha \mathrm{HR}^{2}+$ $\beta$ HR $+\chi$, where $\alpha=3 \times$ a; $\beta=2 \times \mathrm{b} ; \chi=\mathrm{c}$. The IP was defined by the following procedure: IP $=(-\beta-\sqrt{ } \delta) / 2 \alpha$, where $\delta=\beta^{2}-4 \alpha \chi$. SEE was computed as SEE $=$ REE $\mathrm{REE} \times 0.8$ if $\mathrm{HR}<\mathrm{IP}$ and the $\mathrm{P} 3$ equation if $\mathrm{HR}>\mathrm{IP}$; during the day, DEE $=$ REE if $\mathrm{HR}<\mathrm{IP}$ and the P3 equation if $\mathrm{HR}>$ IP.

The thermogenic effect of nocturnal parenteral feeding was calculated as DIT according to the formula DIT $=$ SEE - REE $\times 0.9(18)$.

$\boldsymbol{P} \boldsymbol{A}$. PA was measured in kilo count (kcount) that is the triaxial acceleration unity, simultaneously with TEE assessment, over $24 \mathrm{~h}$ using a triaxial accelerometer (TriTrac-R3D, Professional Products, Reining International, Madison, WI, U.S.A.) on a school day that had no sporting activities. TriTrac-R3D has been shown to be reliable $(19,20)$ and accurate 
(21-24) in the detection of body movement. It was worn firmly attached to the right anterior torso of the subject at the level of the waist, perpendicular to the mid-line of the anterior thigh. The location was consistent for all subjects. All data recorded (written in an activity diary) during motorized movement (car, bus, etc.) were deleted from the analysis of PA.

Statistical analysis. Variables were compared using the nonparametric Wilcoxon paired rank test (differences were deemed significant at $p<0.05$ ). Correlations were tested using Spearman test with significance set at $p<0.05$. Statistical analyses were performed using SPSS (SPSS 7.0 for Windows, SPSS Inc., Chicago, IL, U.S.A.).

\section{RESULTS}

Body composition. Table 2 shows anthropometric data, Zscores for weight/age, Z-scores for height/age, body composition, and BMI of CHPN compared with controls. Weight, height, Z-scores for weight/age, FFM, and FM did not differ between the two groups. Median BMI was significantly higher by $10.1 \%(16.9 \%$; range, $15.5-22.0 \%$, for CHPN versus $15.2 \%$; range, $14.2-18.6 \%$ for controls; $p<0.01$, Wilcoxon rank test) in the CHPN group than in control group. Median $\mathrm{Z}$-score for height/age was significantly higher $(-0.3$; range, $-5.1-2.1$ versus 0.5 ; range, $-1.2-3.8$ for controls; $p<0.05$, Wilcoxon rank test) in the control group than in the CHPN group.

$\boldsymbol{E} E, P A$, and energy intake. REE, PA, and energy intake did not differ between the two groups (Table 3 and Fig. 1). Because of variable durations of awake and sleeping periods, EE data were expressed per minutes. TEE, DEE, and SEE computed with HRMT are shown as a box-plot in Figure 2, and were very similar in the two groups. TEE was $3.4 \mathrm{~kJ} / \mathrm{min}$ (range, 2.2-7.6 $\mathrm{kJ} / \mathrm{min}$ ) for CHPN versus $3.3 \mathrm{~kJ} / \mathrm{min}$ (range, $2.8-6.5 \mathrm{~kJ} / \mathrm{min}$ ) for controls; DEE was $3.9 \mathrm{~kJ} / \mathrm{min}$ (range, $2.6-9.5 \mathrm{~kJ} / \mathrm{min}$ ) for CHPN versus $4.9 \mathrm{~kJ} / \mathrm{min}$ (range, $3.4-8.4 \mathrm{~kJ} / \mathrm{min}$ ) for controls; SEE was $3.1 \mathrm{~kJ} / \mathrm{min}$ (range, $1.6-5.1 \mathrm{~kJ} / \mathrm{min}$ ) for CHPN versus $2.5 \mathrm{~kJ} / \mathrm{min}$ (range, $2.0-4.3 \mathrm{~kJ} / \mathrm{min}$ ) for controls. Moreover, TEE and DEE expressed per kilogram of FFM were very similar in the two groups: TEE was $0.19 \mathrm{~kJ} / \mathrm{min} / \mathrm{kg}$ FFM (range, $0.13-0.27 \mathrm{~kJ} / \mathrm{min} / \mathrm{kg} \mathrm{FFM}$ ) versus $0.18 \mathrm{~kJ} / \mathrm{min} / \mathrm{kg} \mathrm{FFM}$ (range, $0.12-0.24 \mathrm{~kJ} / \mathrm{min} / \mathrm{kg}$ FFM) for CHPN and control children, respectively; and DEE was $0.21 \mathrm{~kJ} / \mathrm{min} / \mathrm{kg} F F M$ (range, $0.14-0.37 \mathrm{~kJ} / \mathrm{min} / \mathrm{kg}$ FFM) versus $0.25 \mathrm{~kJ} / \mathrm{min} / \mathrm{kg}$ FFM $(0.14-0.38 \mathrm{~kJ} / \mathrm{min} / \mathrm{kg}$ FFM) for CHPN and control children, respectively. However, the median of SEE expressed per kilogram FFM was significantly greater $(33.3 \%)$ in the CHPN group $(0.15 \mathrm{~kJ} / \mathrm{min} / \mathrm{kg} \mathrm{FFM}$; range, $0.10-0.23 \mathrm{~kJ} / \mathrm{min} / \mathrm{kg}$ FFM) than in the control group $(0.12 \mathrm{~kJ} / \mathrm{min} / \mathrm{kg} \mathrm{FFM}$; range $0.09-0.21 \mathrm{~kJ} / \mathrm{min} / \mathrm{kg}$ FFM $(p<0.05$, Wilcoxon rank test), as shown in Figure 3. Figure 4 shows the high correlation ( $p=$ 0.0013 , Spearman test) between SEE expressed in kilojoules

Table 3. REE and physical activity $(P A)$ in the two groups children

\begin{tabular}{lcc}
\hline & Parenteral & Controls \\
\hline REE (kJ/d) & $3833.2(2619.9-6423.7)$ & $3803.3(3060.7-6058.4)$ \\
PA (kcounts/d) & $294.5(113.1-392.2)$ & $276.1(161.1-466.8)$ \\
\hline
\end{tabular}

Data given as median and range. per minute per kilogram FFM and the energy flow infused by parenteral expressed in kilojoules per minute per kilogram of weight (median, $0.15 \mathrm{~kJ} / \mathrm{min} / \mathrm{kg}$; range, $0.04-0.20 \mathrm{~kJ} / \mathrm{min} / \mathrm{kg}$ ). Figure 5 shows the high correlation $(p=0.0011$, Spearman test) between the percentage of DIT (median, 6.2\%; range, $0.3-16.7 \%)$ as the percentage of the energy flow infused parenterally (median, $7.1 \mathrm{~kJ} / \mathrm{min}$; range, $2.4-9.2 \mathrm{~kJ} / \mathrm{min}$ ).

\section{DISCUSSION}

$\mathrm{PN}$ is a time-consuming and intrusive procedure. The presence of a stoma and a central venous catheter can decrease routine diurnal PA in patients treated with PN. Modifications to the level of PA as well as reduced TEE should be anticipated, and could interfere with energy requirements. The best way to assess the energy needs of children is to measure TEE (25). Our study evaluated the impact of PN on TEE and PA in CHPN using HRMT and triaxial accelerometry. To the best of our knowledge, the present study is the first to address the question of TEE and PA in children treated with a HPN program. Twenty-two subjects participated in this study: none were obese, weights were in the normal range for age, FFM and Z-scores for weight/age did not differ between the two groups of children. FFM was performed using a $50-\mathrm{Hz}$ bioimpedance meter that was validated for use in children (10). Z-scores for weight/age of both controls and CHPN were in the normal range for age, but were very wide in CHPN (13). Z-scores for weight/age of both controls and CHPN were in the normal range for age, but were significantly lower in CHPN group (13). Moreover, BMI of CHPN was significantly higher than in controls. There was a trend for the FM to be higher in CHPN than in the control group $(p=0.09)$. These finding could indeed indicate that CHPN have growth failure compared with normal children. As none of the CHPN patients had growth retardation, the other explanation is that CHPN patients showed a trend to be fatter than normal children (Table 1). When we paired our patients with controls, we probably favored weight rather than height agreement. We do not think that these differences could have influence results of EE inasmuch as REE and PA were similar $(p=0.929$ and $p=0.859$, respectively) in the two groups.

The power of our study to show a significant difference in TEE (the main criteria of our study) could be calculated $a$ posteriori according to the results we found. Using data (mean: $\mu_{1}=5825 \mathrm{~kJ} / \mathrm{d}, \mu_{2}=5425 \mathrm{~kJ} / \mathrm{d}, \Delta=400 \mathrm{~kJ} / \mathrm{d}$; and SD: $\mathrm{SD}_{1}$ $=2370 \mathrm{~kJ} / \mathrm{d} ; \mathrm{SD}_{2}=1580 \mathrm{~kJ} / \mathrm{d}$ ) and a unilateral test with $\alpha=$ $5 \%$, the power of our test is $1-\beta=13.5 \%\left(\mathrm{Z}_{1-\beta}=1.165\right)$. This poor power indicates that the number of subjects needed to give a statistical difference was not obtained. Using a unilateral test, $\alpha=5 \%$ and $1-\beta=80 \%$, the number a subjects needed to detect a significant difference of $7 \%$ would be 383 per group. Due to the constraints (technical and strict inclusion criteria) of this study and the relatively low number of children on HPN in the participating centers (100 total in France distributed among five HPN authorized centers, two of which participated in this study), it was not possible to include more patients. However, results obtained in patients and con- 
$\mathrm{kJ} / \mathrm{min}$

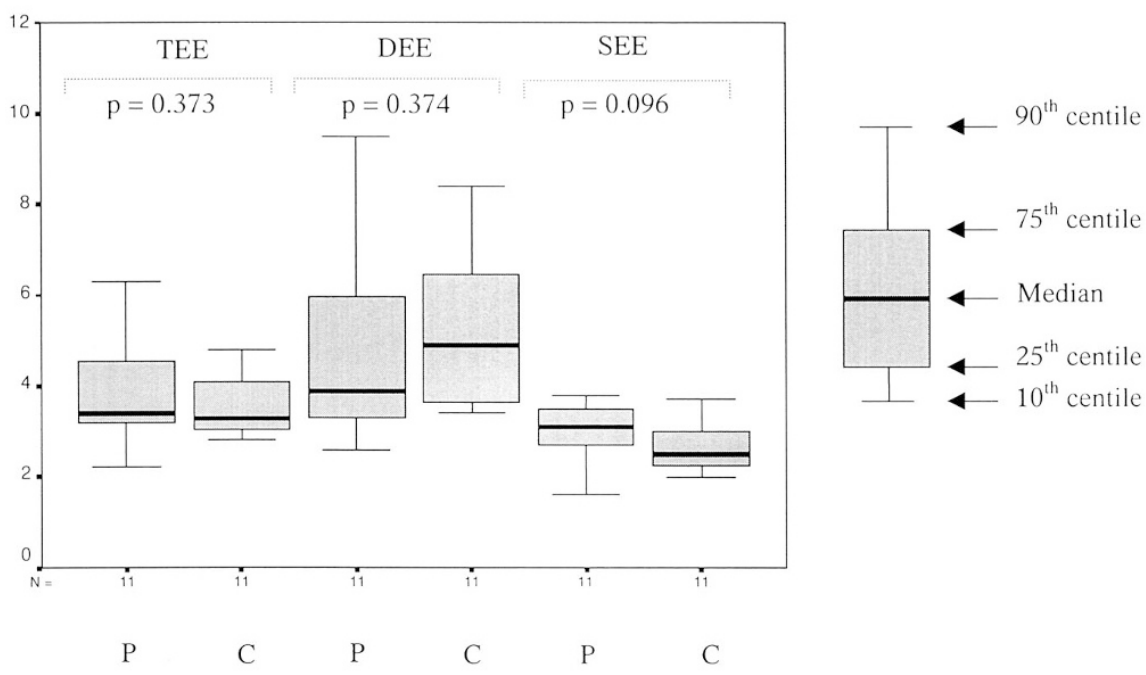

$\mathrm{P}=$ Parenteral $; \mathrm{C}=$ Control

Figure 2. Total energy expenditure (TEE), diurnal energy expenditure (DEE) and sleeping energy expenditure (SEE) in kJ/min in the two groups of children. $P$, parenteral; $C$, control.

\section{$\mathrm{kJ} / \mathrm{min} / \mathrm{kgFFM}$}
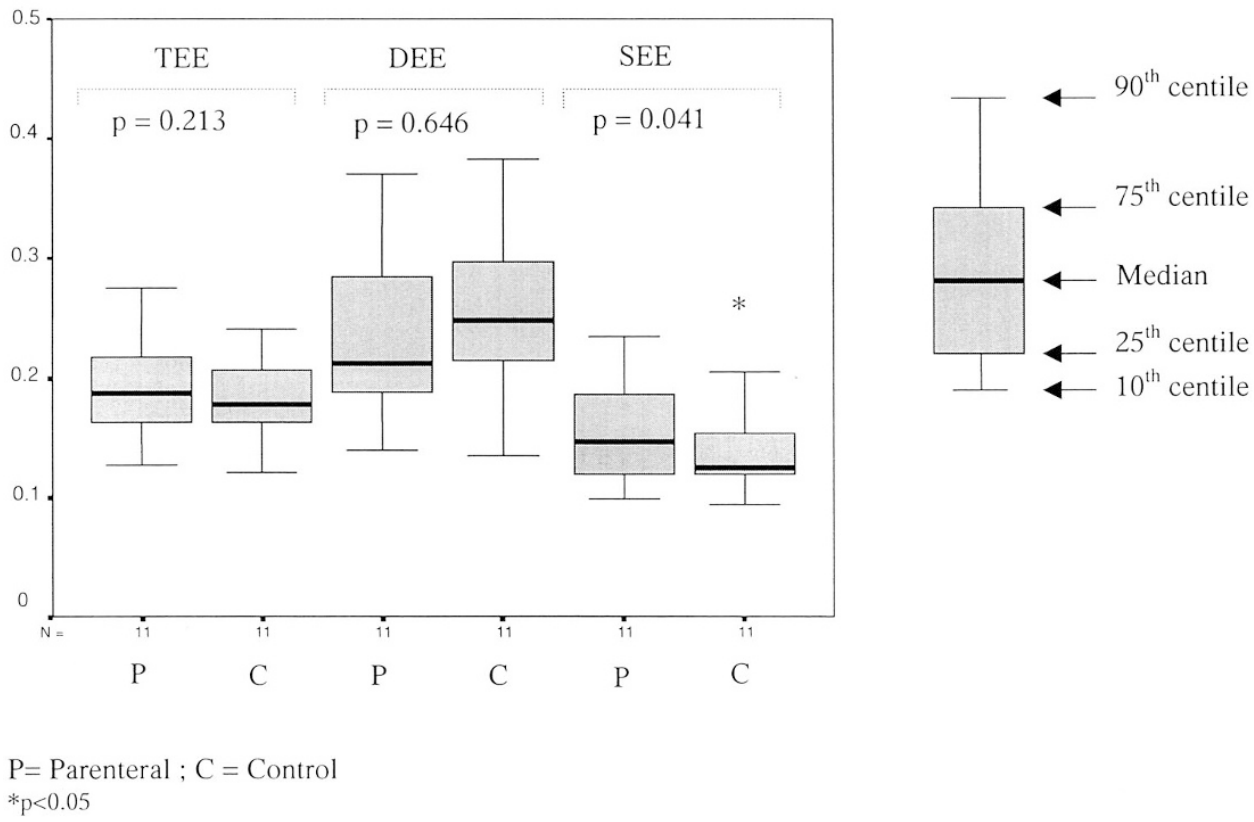

$$
{ }_{* p}<0.05
$$

Figure 3. Total energy expenditure (TEE), diurnal energy expenditure (DEE) and sleeping energy expenditure (SEE) in $\mathrm{kJ} / \mathrm{min} / \mathrm{kg}$ of fat free mass in the two groups of children. $P$, parenteral; $C$, control. ${ }^{*} p<0.05$.

trols were very close (Fig. 2) and $p$ values were quite high, which supported our conclusions.

Eight children presented diseases associated with potential nutrient losses, chronic intractable diarrhea $(n=5)$ and short bowel syndrome $(n=3)$, and six children had a stoma. An increased energy intake could be hypothesized in such conditions. Surprisingly, the TEE of these children were not different from paired controls. This could be explained by the fact that all these patients were in stable condition on HPN when studied, and oral intakes were very limited (median ratio parenteral/oral intake: $99.7 \%$; range, $44.4-100 \%$ ) to limit diarrhea, stoma output, and nutrient losses.

REE was similar between two groups (Table 3). Respiratory quotient (RQ), measured by IC at rest, was similar in the two groups, median, 0.8 (range, 0.7-0.75) for CHPN versus 0.8 (0.71-0.78) for controls, and was in agreement with previous data published for PN in adults (26-28). This finding suggests that CHPN have a normal fasting metabolism and are able to 


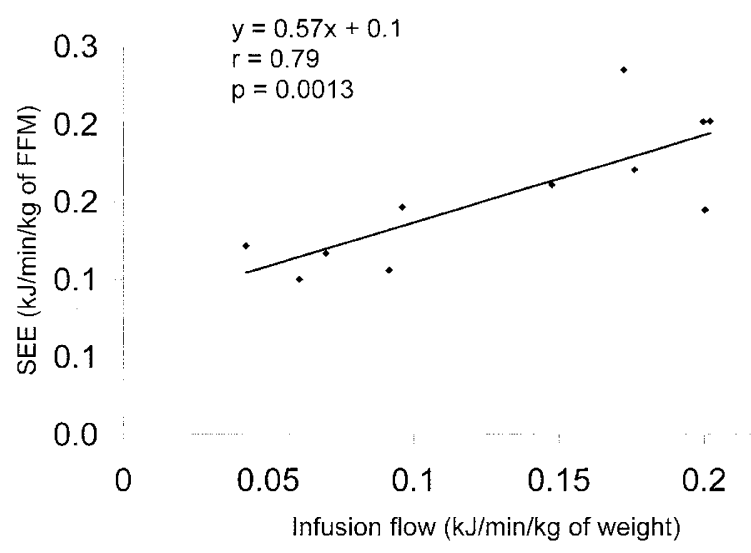

Figure 4. Relationship between sleeping energy expenditure (SEE) expressed in $\mathrm{kJ} / \mathrm{min}$ per kilogram FFM and the energy flow rate infused by parenteral nutrition in $\mathrm{kJ} / \mathrm{min}$ per kilogram of weight.

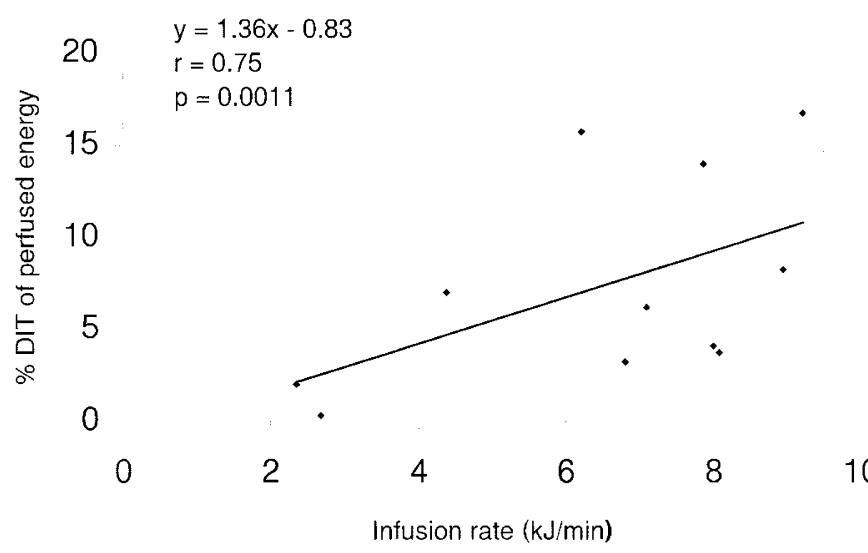

Figure 5. Relationship between the diet induced thermogenesis as the percentage of energy flow rate infused by parenteral nutrition $\mathrm{kJ} / \mathrm{min}$.

mobilize fat stores and oxidated fatty acids after a overnight fast, as controls (29-32). As shown in Table 1, the distributions of the intake of glucids, protein, and fats were similar in the two groups. Our data on TEE clearly show that HPN in children with digestive disease interferes with neither TEE nor PA. TEE was 4,917.4 kJ/d (range, 3,197.3-10,943.8 kJ/d) for CHPN versus $4,766.7 \mathrm{~kJ} / \mathrm{d}$ (range, 3984.1-9391.1 kJ/d) for controls, and were consistent with those obtained from children and adolescents using the doubly labeled method (33-35). TEE computed by HRMT can separate DEE from SEE using the method recently described (18). SEE of CHPN and controls were in accordance with those obtained from children and adolescents using IC $(27,36-37)$. DEE and SEE were similar in the two groups, suggesting that CHPN have the same routine DEE and PA as normal children. Therefore, nocturnal PN does not affect routine diurnal PA or time of sleep (time spent sleeping did not differ between the two groups). This could account for the contribution of FFM to REE and SEE (38-44). SEE expressed per kilogram FFM was significantly greater in the CHPN group. In patients receiving HPN, SEE measured was above SEE calculated by the formula REE $\times 0.9$, which was shown to be accurate in fasting normal children (18). Indeed, we hypothesized that the difference between measured SEE and calculated SEE by the formula REE $\times 0.9$ was due to the DIT. This was suggested by the high correlation between
SEE expressed in kilojoules per minute per kilogram FFM and the energy rate perfused by PN expressed in kilojoules per minute per kilogram of weight. This high correlation could be attributed to the thermogenic effects of nocturnal PN (32, 45-47). Indeed, when DIT was calculated as the additional EE (Fig. 5) above SEE $(\mathrm{SEE}=$ REE $\times 0.9)(18)$, which was in accordance with data previously published $(32,48-52)$, a high correlation was shown between the percentage of DIT for infused energy and the energy flow rate infused by PN.

PA can be considered an important determinant of the quality of life. Accelerometry indicated similar levels of routine PA in the two groups. In contrast, a previous study of adults showed severely reduced levels of PA and a reduction in the quality of life in patients with HPN compared with subjects with short bowel syndrome not receiving PN (53). This reduction in the quality of life was attributed to a severe decrease in PA. In fact, the severe decrease in PA observed in adults was probably due to the low employment rate among these patients, and perhaps to the difference in severity of the underlying digestive disease between adults and children. All the CHPN in our study could attend school and had apparently normal routine diurnal activities.

Our results suggest that the energy requirements of children on long-term cyclic HPN are no different from those of controls, and that PN does not interfere with PA. The energy requirements of CHPN in a stable condition presenting with digestive disease are the same as for healthy control subjects.

Acknowledgments. The authors thank the children and their parents for taking part in this study. We thank Cristel Michel (CIC-9202-INSERM-AP-HP, Hôpital Robert Debré, Paris) for his technical assistance and Sabine Patte (Service de Nutrition, Clinique de Pédiatrie, Hôpital Jeanne de Flandre, CHRU de Lille) for dietetic analysis.

\section{REFERENCES}

1. Fleming CR, Remington M 1981 Intestinal failure. In: Hill GL (ed) Nutrition and the Surgical Patient. New York, Churchill Livingstone, pp 219-235

2. Wilmore DW 1989 The history of parenteral nutrition. In: Baker RD, Baker SS, Davis AM (eds) Pediatric Parenteral Nutrition. Chapman \& Hall, New York, pp 1-6

3. Cannon RA, Byrne WJ, Ament ME, Gates B, O'Connor M, Fonkalsrud EW 1980 Home parenteral nutrition in infants. J Pediatr 96:1098-1104

4. Gibson RS 1990 Principles of Nutritional Assessment. New York, Oxford University Press

5. Hendricks KM, Walker WA 1990 Manual of Pediatrics Nutrition, 2nd Ed. BC Decker, Toronto, ,Canada

6. 1990 Quality assurance for pediatric nutrition conditions. In: Dietitians in Pediatric Practice, Chicago. American Dietetic Association, pp 15-24

7. Anonymous 1989 Recommended Dietary Allowances, 10th Ed. Washington, DC, National Academy Press, pp 63-128

8. Greene HL, Hambidge KM, Schanler R, Tsang RC 1988 Guidelines for the use of vitamins, trace elements, calcium, magnesium, and phosphorus in infants and children receiving total parenteral nutrition: report of the Subcommittee on Pediatric Parenteral Nutrient Requirements from the Committee on Clinical Practice Issues of the American Society for Clinical Nutrition. Am J Clin Nutr 48:1324-1342

9. Martin A 2001 Apports conseillés pour la population française, 3rd Ed. Paris, France, AFSSA-CNERNA-CNRS

10. Schaefer F, Georgi M, Zieger A, Schärer K 1994 Usefulness of bioelectric impedance and skinfold measurements in predicting fat-free mass derived from total body potassium in children. Pediatr Res 35:617-624

11. Brook GCD 1971 Determination of body composition of children from skinfold measurements. Arch Dis Child 46:182-184

12. Durnin JVGA, Rahaman MM 1967 The assessment of the amount of fat in the human body from measurements of the skinfold thickness. Br J Nutr 21:681-689

13. Sempé M, Pédron G, Roy-Pernot MP 1979 Auxology: Methods and Sequences. Paris, Théraplix 
14. Block G 1982 A review of validations of dietary assessment methods. Am J Epidemiol 115:492-505

15. Anonymous 1994 Centre informatique sur la qualité des aliments. Répertoire généra des aliments. Tables de compositions. Editions Médicales Internationales Lavoisier, Paris

16. Spurr GB, Prenctice AM, Murgatroyed PR, Goldberg GR, Reina JC, Christman NT 1988 Energy expenditure from minute-by-minute heart-rate recording: comparison with indirect calorimetry. Am J Clin Nutr 48:552-559

17. Béghin L, Budniok T, Vaksmann G, Boussard-Delbecque L, Michaud L, Turck D, Gottrand F 2000 Simplification of the method of assessing diurnal and nightly energy expenditure in children using heart rate monitoring calibrated against open circuit indirect calorimetry. Clin Nutr 19:425-435

18. Béghin L, Michaud L, Guimber D, Vaksmann G, Turck D, Gottrand F 2002 Assessing sleeping energy expenditure in children using heart-rate monitoring calibrated against open-circuit indirect calorimetry. Br J Nutr 88:533-543

19. Bouten CVC, Westerterp KR, Verduin M, Kodde R, Janssen JD 1994 Assessment of energy expenditure for physical activity using a triaxial accelerometer. Med Sci Sports Exerc 26:1516-1523

20. Bouten CVC, Koekkoek KTM, Verduin M, Kodde R, Janssen JD 1997 A triaxial accelerometer and portable data processing unit for the assessment of diurnal physical activity. IEEE Trans Biomed Eng 38:211-229

21. Westerterp KR 1999 Physical activity assessment with accelerometers. Int J Obes Relat Metab Disord 23:45-49

22. Coleman KJ, Saelens BE, Wiedrich-Smith MD, Finn JD, Epstein LH 1997 Relationships between TriTrac-R3D vectors, heart rate, and self-report in obese children. Med Sci Sports Exerc 29:1535-1542

23. Welk GJ, Corbin CB 1995 The validity of the TriTrac-R3D activity monitor for the assessment of physical activity in children. Res Q Exerc Sport 66:1-8

24. Masse LC, Fulton JE, Watson KL, Heesch KC, Kohl III HW, Blair SN, Tortolero SR 1999 Detecting bouts of physical activity in a field setting. Res Q Exerc Sport 70:212-219

25. Torun B, Davies PSW, Livingtone MBE, Paolisso M, Sackett R, Spurr GB 1996 Energy requirements and dietary energy recommendations for children and adolescents 1 to 18 years old. Eur J Clin Nutr 50(suppl 1):S37-S81

26. Lerebours E, Rimbert A, Hecketsweiler B, Hellot MF, Denis P, Colin R 1988 Comparison of the effects of continuous and cyclic nocturnal parenteral on energy expenditure and protein metabolism. JPEN J Parenter Enteral Nutr 12:360-364

27. Pullicino E, Goldberg GR, Elia M 1991 Energy expenditure and substrate metabolism measured by $24 \mathrm{~h}$ whole-body calorimetry in patients receiving cyclic and continuous total parenteral nutrition. Clin Sci 80:571-582

28. Just B, Messing B, Darmaun D, Rongier M, Camillo E 1990 Comparison of substrate utilization by indirect calorimetry during cyclic and continuous total parenteral nutrition. Am J Clin Nutr 51:107-111

29. Askanazi J, Carpentier YA, Elwyn DH, Nordenstrom J, Jeevanandam M, Rosenbaum SH, Gump FE, Kinney JM 1980 Influence of total parenteral nutrition on fue utilization in injury and sepsis. Ann Surg 191:40-46

30. Elwyn DH, Kinney JM, Askanazi J 1981 Energy expenditure in surgical patients Surg Clin North Am 61:545-546

31. Quebeman EJ, Ausman RK, Scneider TC 1982 A re-evaluation of energy expenditure during parenteral nutrition. Ann Surg 195:282-286

32. Al-Jaouni R, Schneider SM, Rampal P, Hébuterne X 2002 Effect of age on substrate oxidation during total parenteral nutrition. Nutrition 18:20-25

33. Livingstone MBE, Coward WA, Prenctice AM, Davies PSW, Strain JJ, McKenna PG Mahonet CA, White JA, Stewart CM, Kerr MJJ 1992 Diurnal energy expenditure in free-living children: comparison of heart-rate monitoring with the $\left({ }^{2} \mathrm{H}_{2}{ }^{18} \mathrm{O}\right)$ doubly labelled water method. Am J Clin Nutr 56:343-352
34. Emons HJG, Gronenboom DC, Westerterp KR, Saris WHM 1992 Comparison of heart rate monitoring combined with indirect calorimetry and the doubly labelled water $\left({ }^{2} \mathrm{H}_{2}{ }^{18} \mathrm{O}\right)$ method for the measurement of energy expenditure in children. Eur J Appl Physiol 65:99-103

35. Maffeis C, Pinelli L, Zaffanello M, Schena F, Iacumin P, Schutz Y 1995 Diurnal energy expenditure in free living conditions in obese and non-obese children: comparison of doubly labelled water $\left({ }^{2} \mathrm{H}_{2}{ }^{18} \mathrm{O}\right)$ method and heart-rate monitoring. Int J Obes Relat Metab Disord 19:671-677

36. Klausen B, Toubro S, Astrup A 1997 Age and sex effects on energy expenditure. Am J Clin Nutr 65:895-907

37. Bracco D, Morin O, Liang H, Jéquier E, Borger AG, Schutz Y 1996 Changes in sleeping and basal energy expenditure and substrate oxidation induced by short term thyroxin administration in man. Obes Res 4:213-219

38. Elia M 1992 Organ and tissue contribution to metabolic rate. In: Kinney JM, Tucke HN (eds) Energy metabolism: Tissue Determinants and Cellular Corollaries. Raven Press, New York pp 61-77

39. Illner K, Brinkmann G, Heller M, Bosy-Wesphal A, Muller MJ 2000 Metabolically active components of fat free mass and resting energy expenditure in non-obese adults. Am J Physiol Endocrinol Metab 278:E308-E315

40. Sparti A, Delany JP, de la Bretone JA, Sander GE, Bray GA 1997 Relationship between resting metabolic rate and the composition of the fat-free mass. Metabolism 46:1225-1230

41. Svendsen OL, Hassager C, Christiansen C 1997 Impact of regional and total body composition and hormones on resting energy expenditure in overweight postmenopausal women. Metabolism 46:1225-1230

42. Garby L, Lammert O, Kock K, Thobo-Carlsen B 1992 Weights of brain, heart, liver, kidneys, and spleen in healthy and apparently healthy adult Danish subjects. Am J Hum Biol 5:291-296

43. Deriaz O, Fournier G, Tremblay A, Despres JP, Bouchard C 1992 Lean-body-mass composition and resting energy expenditure before and after long-term over-feeding. Am J Clin Nutr 56:848-856

44. Zhang K, Sun M, Werner P, Kovera AJ, Albu J, Pi-Sunyer FX, Boozer CN 2002 Sleeping metabolic rate in relation to body mass index and body composition. Int J Obes Relat Metab Disord 26:376-383

45. Thiebaud D, Acheson K, Schutz Y, Felber JP, Golay A, Defronzo RA, Jequier E 1983 Stimulation of thermogenesis in man following combined glucose-long chain triglyceride infusion. Am J Clin Nutr 37:603-611

46. Shaw SN, Elwyn DH, Askanazi J, Iles M, Schwaz Y, Kinney JM 1983 Effects of increasing nitrogen intake on nitrogen balance and energy expenditure in nutritionally depleted adult patients receiving parenteral nutrition. Am J Clin Nutr 37:930-940

47. Pittet P, Gygax P, Jequier E 1974 Thermic effect of glucose and amino-acids in man studied by direct and indirect calorimetry. Br J Nutr 31:343-349

48. Romon M, Edme JL, Boulenguez C, Lescroart JL, Frimat P 1993 Circadian variation of diet-induced thermogenesis. Am J Clin Nutr 57:476-480

49. Kunz I, Klaus S, Kallies B, Schorr U, Sharma AM 2000 Kinetic analysis of the thermic effect of food and its relationship to body composition in humans. Metabolism 49:1340-1345

50. Acheson KS, Ravussin E, Wahren J, Jequier E 1984 Thermic effect of glucose in man: obligatory and facultative thermogenesis. J Clin Invest 74:1572-1580

51. Kinabo JL, Durnin JV 1992 Thermic effect of food in man. Effect of meal composition, and energy content. Br J Nutr 64:37-44

52. Piers LS, Soares MJ, Makan T, Shetty PS 1992 Thermic effect of a meal. 1 Methodology and variation in normal young adults. Br J Nutr 67:165-175

53. Jeppesen PB, Langholz E, Mortasen PB 1999 Quality of life in patients receiving home parenteral nutrition. Gut 44:844-852 